Canadian

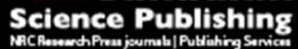

Canadian Journal of Physiology and Pharmacology Revue canadienne de physiologie et pharmacologie

\title{
Effects of Telmisartan and Pioglitazone on High Fructose Induced Metabolic Syndrome in Rats
}

\begin{tabular}{|r|l|}
\hline Journal: & Canadian Journal of Physiology and Pharmacology \\
\hline Manuscript ID & cjpp-2016-0090.R1 \\
\hline Danuscript Type: & Article \\
\hline Complete List of Authors: & $\begin{array}{l}\text { Shahataa, Mary; Beni Suef University Faculty of Medicine } \\
\text { Mostafa-Hedeab, Gomaa; Beni Suef University Faculty of Medicine; Faculty } \\
\text { of medicine Al jouf University } \\
\text { Ali, Esam; Cairo University Kasr Alainy Faculty of Medicine } \\
\text { Mahdi, Emad; Beni Suef University Faculty of Veterinary Medicine } \\
\text { Mahmoud, Fatma; Cairo University Kasr Alainy Faculty of Medicine }\end{array}$ \\
\hline Keyword: & \\
\hline & \\
\hline
\end{tabular}

SCHOLARONE ${ }^{m}$

Manuscripts 


\title{
Effects of Telmisartan and Pioglitazone on High Fructose Induced
}

\section{Metabolic Syndrome in Rats}

Mary Girgis Shahataa ${ }^{1}$, Gomaa Mostafa-Hedeab ${ }^{1,2}$, Esam Fouaad Ali $^{3}$, Emad ahmed Mahdi ${ }^{4}$, Fatma Abd Elhaleem Mahmoud ${ }^{3}$

\author{
${ }^{1}$ Pharmacology department - Faculty of Medicine- Beni Suef \\ University - Egypt \\ ${ }^{2}$ pharmacology department - faculty of medicine - Al Jouf \\ University - Saudia Arabia \\ ${ }^{3}$ Pharmacology department - Faculty of Medicine- Cairo \\ University - Egypt \\ ${ }^{4}$ pathology department - faculty of veterinary medicine - Beni \\ Suef University - Egypt
}

\section{Corresponding author:}

Dr Gomaa Mostafa-Hedeab

- Address : Pharmacology department - Faculty of Medicine- Beni Suef University - Egypt

- Telephone:+201124225264

- Postal code: 62511

- Fax: +20 (82) 2333367

- Email:_Gomaa_hedeab@yahoo.com goma.ghonima@med.bsu.edu.eg 


\begin{abstract}
Metabolic syndrome (MS) is a cluster of hypertension, insulin resistance, dyslipidaemia and hyperuricemia. This study was designed to assess the effect of telmisartan and pioglitazone on high fructose induced metabolic syndrome.35 Male albino rats were classified into 5 groups: A: Normal diet-fed; B: High Fructose-fed (HFD) subdivided into B1 (HFD only), B2 (telmisartan 5mg/kg), B3 (pioglitazone10mg/kg) and B4 (telmisartan + pioglitazone). Drugs started 4 weeks after staring HFD \& lasts for 4 weeks. Body weight (BW), blood pressure (BP) measurement, estimation of the level of fasting glucose, fasting insulin, uric acid (UA), total cholesterol, triglycerides (TG), high density lipoprotein (HDL-c), low density lipoprotein (LDL-c), blood urea nitrogen (BUN), creatinine and (nitric oxide) NO were done. Compared to group-B1:Telmisartan sig decrease BP, BW, serum glucose, insulin, UA, urea, cholesterol, TGA, LDL and sig increase HDL; pioglitazone sig decrease BP, serum glucose, insulin, UA, urea, creat., cholesterol, TGA, LDL and sig increase HDL. Co-administration of Pioglitazone + telmisartan sig decrease insulin, urea and creat compared to telmisartan alone. Combined telmisartan plus pioglitazone allow better control of BP, hyperglycaemia, insulin resistance and the amelioration of BW increase that may be associated with pioglitazone treatment.
\end{abstract}

Keywords: Metabolic syndrome, Telmisartan, Pioglitazone, Body weight, Blood pressure, dyslipidaemia, uric acid, insulin resistance 


\section{Introduction:}

Metabolic syndrome (MS) is a worldwide problem that is currently receiving much exploration, both in experimental animals and in the clinic (Alam et al. 2016; Liu et al. 2016; Rabie et al. 2015; Vu et al. 2016). MS is a combination of medical disorders which increases the risk of cardiovascular disease and diabetes (Benson et al. 2004). MS includes hypertension, insulin resistance (IR), dyslipidaemia and hyperuricemia which is strongly associated with risk of impaired glucose metabolism and diabetes (Puig and Martinez 2008).

The renin-angiotensin system (RAS) plays an important role in the pathophysiological consequences of MS and many researchers in clinical trials showed the significant benefits of RAS blockade for end-organ protection in MS (Galle et al. 2008). Either inhibition of RAS or Block of angiotensin receptors is thought to ameliorate MS criteria (Rabie et al. 2015), may be through improvement of insulin sensitivity independent of changes in blood pressure (Mori et al. 2007), prevention of weight gain in addition (de Kloet et al. 2010), reduction in liver injury, attenuation of oxidative stress parameters and hepatic expressions of inflammatory and fibrotic markers (Rabie et al. 2015) 
Telmisartan is an orally active antagonist of angiotensin II type I receptors $\left(\mathrm{AT}_{1}\right)$, it has the highest affinity for the $\mathrm{AT}_{1}$ receptors among the available AT1 antagonists (Kakuta et al. 2004).

Pioglitazone is thiazolidinedione agent that improve glucose homeostasis in type 2 diabetes by decreasing insulin resistance (Olefsky 2000) especially in adipose tissue and muscles (Finelli and Tarantino 2012a). In addition, it significantly decreases the risks of the dangerous cardiovascular side effects and strokes that are common in patients with high-risk type 2 diabetes (Dormandy et al. 2005). The Pioglitazone has agonistic activity of nuclear receptor, peroxisome proliferator-activated receptor gamma (PPAR- $\gamma$ ) which is expressed in endothelium, vascular smooth muscle cells and is thought to be responsible for atherosclerosis (Little et al. 2008).

The aim of the present work is to study the effect of telmisartan on HFD induced MS in rats in comparison to anti-diabetic drug pioglitazone. 


\section{Materials and Methods}

\section{Drugs and Chemicals:}

Telmisartan: (Bohringer Ingelheim, Germany), Allopurinol: (GSK, Egypt), Pioglitazone: (Takeda, Egypt) to be dissolved in distilled water to a concentration of $1 \mathrm{mg} / \mathrm{ml}$. Fructose: Uni fructose powder (Universal Industrial Pharmaceutical Co. (UNIPHARMA - Egypt).

\section{Animals:}

35 adult male Sprage Dawley rats weighing (190-200 g) were handled according to the guidelines of local ethical committee that it adhere to the provisions of the Declaration of Helsinki in 1995 (as revised in Edinburgh 2000). The rats were housed in metal cages under ordinary room temperature, exposed to natural daily light-dark cycles. They were fed a standard chow diet composed. They were allowed free access of water. Animals were divided into 2 main groups.

Group A: (7 rats) (Non-fructose-fed) received vehicle (distilled water, 1 $\mathrm{ml} / \mathrm{kg}$ ), served as negative control group

Group B: (28 rats) Fructose-fed rats were fed high fructose diet (HFD) for 8 weeks $(60 \%$ HFD consists of fructose mixed with normal diet in a ratio of 6:4 (Nagi et al. 1995) and further subdivided into 4 groups, 7 rats each:

Group B1: HFD diet only + (water, $1 \mathrm{ml} / \mathrm{kg}$ ) served as positive control. 
Group B2: HFD + Telmisartan (5 mg/kg) (Zanchi et al. 2007).

Group B3: HFD + Pioglitazone (10 mg/kg) (Suzuki et al. 1997) .

Group B4: HFD + Telmisartan + Pioglitazone in the above mentioned doses.

All drugs were given daily orally by gavage starting 4 weeks from HFD feeding and last for 4 weeks:-

- Body weight (BW) of each rat was recorded at the start and at the end of the $8^{\text {th }}$ week of the experiment.

- Measurement of Systolic (SBP), diastolic (DBP) and mean blood pressure (MBP) digitally were done in conscious rats using a tail-cuff sphygmomanometer a non-invasive blood pressure measurement system (Biosynthesis Biotechnology TSE-system, Homburg, Germany), at the start and at the end of the $8^{\text {th }}$ week of the experiment. The mean value of three consecutive measurements was obtained. All animals were preconditioned daily for $\mathrm{BP}$ measurements one week before the experiment.

\section{- Biochemical examination}

After 6-8 fasting hours, retro-orbital $5 \mathrm{ml}$ blood sample was drown under inhalation anaesthesia, centrifuged at 3000 round/minute for 20 minutes, the serum was transferred into clean vials and stored at $-20^{\circ} \mathrm{C}$. 
Using commercially available-ready to use kits for estimation of the level of glucose, insulin (Monobind Inc, USA), UA, total cholesterol, TG, HDL-c, LDL-c, BUN, creatinine (Biodiagnostic, Egypt) and NO (IBL International GmbH, Germany) according to the manufacturer guidelines.

\section{Homeostasis assessment of insulin resistance (HOMA-IR) (IR index)}

Insulin resistance (IR) was determined using (The Homeostasis assessment of insulin resistance (HOMA-IR) (IR index). It was calculated by using the fasting serum glucose and insulin levels according to Matthews et al. The equation: HOMA-IR = fasting glucose $(\mathrm{mg} / \mathrm{dl}) \times$ fasting insulin $(\mu \mathrm{U} / \mathrm{L}) / 450$ (Matthews et al. 1985) .

\section{Histopathological examination of rat knee joints}

At the end of experiment, animals were sacrificed. Right/left rats knee joints of each animal were removed into $10 \%$ neutral buffered formalin, processed for complete decalcification in EDTA, embedded in paraffin, sectioned longitudinally at $5 \mu \mathrm{m}$ and stained with hematoxylin and eosin for histopathology study

\section{Statistical analysis}

Results were expressed as Mean \pm Standard Deviation (SD) and analysed for statistically significant differences using one way analysis of variance 
(ANOVA) followed by the LSD (Least Significant Difference) post analysis test to compare the means from different groups. $P$ value $<0.05$ was considered significant. SPSS 17 for windows was used for statistical calculations (San Diego, CA, USA). 


\section{Results}

HFD for eight weeks resulted in appearance of classic symptoms of MS in the form of significant increase in BW, SBP, DBP, MBP, serum glucose and insulin, IR, UA, urea and creatinine, serum TG, total cholesterol, LDL and significant decrease in serum NO level and HDL-c levels compared to normal non medicated group-A.

\section{Body Weight:}

Telmisartan (group B2) and combined telmisartan with pioglitazone (group B3) significantly decreased mean BW; while, pioglitazone treatment (group B4) didn't result in significant difference in rats BW compared to group B1. On the other hand, adding telmisartan to pioglitazone in group B4 result in significant reduction of BW compared to that produced by pioglitazone alone (B2).

In all situations, there was significant higher mean BW in all groups compared to normal control group i.e. the tested drugs ameliorated but not normalized the BW effects of HFD (Table 1).

\section{Blood Pressure:}

Telmisartan (group B2), pioglitazone (group B 3) significantly decreased mean BP compared to group B1. Combined therapy with 
pioglitazone and telmisartan didn't show additive synergistic or potentiating action over using each drug alone.

On the other hand, there was significantly higher blood pressure in all groups compared to normal control non medicated group A i.e. the currently used drugs alone or in combination couldn't normalize BP but ameliorate it (Table 2).

\section{Glucose and insulin}

Telmisartan (group B2), pioglitazone (group B 3) or combined telmisartan with pioglitazone (group B4) significantly decreased mean serum glucose and insulin levels compared to group B1. Furthermore, serum glucose was normalized by pioglitazone and combined telmisartan plus pioglitazone.

On the other hand, serum insulin levels were normalized by pioglitazone only. In addition, pioglitazone resulted in significantly lower mean insulin level compared to telmisartan.

While adding telmisartan to pioglitazone resulted in insignificant changes compared to those produced by pioglitazone alone in mean serum glucose and insulin levels (Table 3).

\section{Insulin Resistance (IR):}

Telmisartan, pioglitazone and combined telmisartan with pioglitazone significantly decreased IR compared to group B1. In 
addition, pioglitazone significantly decreased IR compared to telmisartan. Furthermore, addition of telmisartan to pioglitazone didn't result in further decrease in IR compared to telmisartan alone. Neither telmisartan, pioglitazone nor their combination could normalize the IR (Figure 1).

\section{Nitric Oxide}

Telmisartan and pioglitazone resulted in insignificant increase in serum NO level compared to that of group-B1. Combined telmisartan with pioglitazone resulted in significant increase in NO level compared to that in group-B1.Adding pioglitazone to telmisartan resulted in insignificant changes in NO level compared to the effect of each drug alone (Table 3).

\section{Uric Acid}

Telmisartan, pioglitazone and combined telmisartan with pioglitazone significantly decreased the mean serum UA levels compared to group-B1. Combined pioglitazone to telmisartan in group B 4 resulted in insignificant differences compared to the effect of each drug alone (Table 4).

\section{Urea \& Creatinine}

Pioglitazone and combined telmisartan with pioglitazone significantly decreased mean serum urea and creatinine levels compared to group B1 with insignificant differences from that in normal control non 
medicated group A i.e. they normalized these parameters compared to B1 non treated group.

While telmisartan in group B2 significantly decreased mean serum urea with insignificant change in mean creatinine level. Pioglitazone treatments significantly decreased mean creatinine and urea levels compared to telmisartan.

Co-administration of pioglitazone and telmisartan resulted in no more significant reduction in neither mean serum creatinine nor urea levels, than those produced by pioglitazone alone (Table 4).

\section{Dyslipidaemia:}

Telmisartan, pioglitazone or combined telmisartan with pioglitazone significantly decreased $\mathrm{TG}$, total cholesterol and LDL-c; whereas significantly increased HDL level compared to group-B1.

Pioglitazone normalized serum TG, LDL-c or HDL-c and total cholesterol levels, whereas telmisartan normalized only total cholesterol but can't normalize serum TG, LDL-c or HDL-c.

On the other hand, addition of telmisartan to pioglitazone abolished its ability to normalize serum LDL-c and HDL-c but not TG or cholesterol. Telmisartan decreasing effect of LDL-c levels is less significant than pioglitazone effect (Table 5).

\section{- Histopathological examination of rat knee joints:}


In the group B1, histopathological study of the knee of rats, demonstrated features of acute gouty arthritis in only two animals of the examined rat knee joints in the form of edema, moderate to mild infiltrate of neutrophils and mast cells within the periarticular soft tissues (Fig. 3) compared to that of the control group-A that showed no gouty arthritis lesions within the articular and periarticular soft tissues with normal histological structure (Fig. 2).

Histopathological study of the 7 animals in the groups B2, B 3 and B 4 showed no lesions of gouty arthritis within the articular and periarticular soft tissues (Fig. 4) (Fig. 5) and (Fig. 6) respectively. 


\section{Discussion:}

Fructose is a commonly used sweetener associated with diets (Finelli and Tarantino 2012b). The increase in fructose consumption in high fructose sweetener represents an important contributor to the epidemic MS world wide (Rabie et al. 2015). The HFD induce a deranged lipid profile that is associated with adipose tissue hypertrophy, increased ratios of visceral and epididymal fats to body weight and fatty liver (Finelli and Tarantino 2012b)

The results of the present study showed that administration of HFD to rats for 8 weeks induced signs of MS, in the form of significant increase in BW, Bp, blood glucose, serum insulin, IR, serum triglycerides level, serum cholesterol, serum LDL and decrease serum HDL level with insignificantly decrease in serum NO compared to control rats that didn't receive HFD which is in agreement with previous report (Kelishadi et al. 2014).

Telmisartan significantly ameliorated the increased BW produced by HFD, this is in agreement with (Khan et al. 2011), which may be due to affection of adipocyte biology and stimulation of efficient adipocytes 
formation (Sharma et al. 2002), thus may leads to increase in energy expenditure and decrease in dietary-induced increases in BW and accumulation of visceral fat. It may also be mediated via PPAR $\gamma$ partial agonistic activity that leads to improved glucose and lipid metabolism and prevention of the increase in $\mathrm{BW}$ induced by diet as a result of adipocyte hypertrophy.

While pioglitazone results in insignificant difference in mean BW compared to normal rats which run with results of (Collino et al. 2010) and (Kong et al. 2014) in experimental MS in rats, but against (Haque 2012) in MS patients. The weight gain associated with pioglitazone may be due to increase in fat mass and redistribution of fat from visceral to subcutaneous adipose depot or due to fluid retention (Endo et al. 2011).

The beneficial effect of adding telmisartan to pioglitazone in amelioration of BW in the present study is in agreement with (Zanchi et al. 2007) and (Miyazaki and DeFronzo 2008).

The explanation of this beneficial effect may be a result of prevention of fluid and sodium retention induced by pioglitazone (Endo et al. 2011).

The antihypertensive effect of telmisartan is a well-known and established therapeutic indication ( $\mathrm{Xu}$ and Liu 2013), which is due to $\mathrm{AT}_{1}$ receptor block that results in a fall of peripheral resistance (Werner et al. 2008) or may be through a PPAR $\gamma$-dependent increase in eNOS 
expression and activity (Yuen et al. 2011). This is apparently obvious via insignificant difference in BP effects between telmisartan and pioglitazone (which is also a PPAR - $\gamma$ modifying drug) and when concurrently administered; such observation is in accordance with (Knorr et al. 2011).

Telmisartan could enhance NO release and reduce oxidative stress (Xu and Liu 2013). Anti-oxidant activities didn't investigated in the present study; Alternatively NO results showed insignificant increase in telmisartan or pioglitazone treated groups compared to non-treated group; such a result confirms the observation of (BARUTÇUOĞLU et al. 2010) who stated that telmisartan didn't improve serum NO either in essential hypertensive or diabetic hypertensive patients although it normalization of $\mathrm{Bp}$.

Another explanation of MS pathogenesis is hyperuricemia that may induce a primary afferent arteriolopathy which may explain hypertension pathogenesis (Mazzali et al. 2001), induce vascular wall thickening leading to severe vasoconstriction. The resulting decrease in renal plasma flow, GFR, and per tubular capillaries (Sanchez-Lozada et al. 2005) leading to ischemia which is a potent stimulus to arterial hypertension. Development of salt-sensitive hypertension in normal rats 
that could be imitated by mild hyperuricemia (Watanabe et al. 2002) supported this explanation.

Pioglitazone significantly decreased BP in fructose-induced (Suzuki et al. 1997), in insulin resistance model in rats (Zanchi et al. 2007), these results are in agreement with our results. Whereas in opposite to results published by (Haque 2012).

The antihypertensive effects of pioglitazone could be due to improving insulin sensitivity, decreasing peripheral vascular resistance and improving endothelial dysfunction (Sung et al. 1999), through stimulation of the production of endothelium-derived vasodilator substances (Goke and German Pioglitazone Study 2002), with their inhibiting effects on various cytokines and the pro-inflammatory transcription factors (Diamant and Heine 2003); however antiinflammatory parameters weren't assessed in the present study.

In the present result, co-administration of both pioglitazone and telmisartan resulted in insignificant change in diastolic, systolic and mean BP compared to telmisartan alone.

In agreement to (Kong et al. 2014), the present results showed absence of additive effect of combined pioglitazone and telmisartan in controlling BP compared to either drug alone. In contrast was the clinical 
studies carried by (Suzuki et al. 2013), who suggested that addition of pioglitazone to candesartan might be a good therapeutic strategy for treating hypertensive-patients with type-2 diabetes.

In the present study, the antihypertensive effect of pioglitazone isn't related to NO levels that run with results of (Shokouh et al. 2013) who found insignificant change in Asymmetric Dimethylarginine (ADMA), the principal endogenous NOS inhibitor, in non-diabetic MS patients treated by pioglitazone.

Telmisartan significantly decreased mean serum glucose and insulin levels compared to non-treated group, such result is in agreement with (Haque 2012), but in contrast to results of (Bahr et al. 2011) in MS patients.

The insulin sensitizing effect of telmisartan has been revealed by (Schupp et al. 2004), through a partial PPAR $\gamma$ agonistic activity, a central regulator of insulin sensitivity. Telmisartan caused a dose-dependent insulin-sensitizing activity via PPAR $\gamma$ activation, leading to augmented GLUT4 protein expression and 2-deoxy glucose uptake, both in basal and insulin-stimulated states of adipocytes and induced adiponectin (Fujimoto et al. 2004). 
Moreover, (Lardizabal and Deedwania 2010) demonstrated the improvement in insulin-stimulated glucose uptake in muscle, hepatic cells and adipose tissue induced by telmisartan is related to PPAR $\gamma$ activation, or may be through its anti-inflammatory processes, free fatty acid concentration and/or metabolism alteration.

Pioglitazone showed significant decrease in mean serum glucose and insulin levels, possibly through stimulation of the expression of genes involved in lipid metabolism such as the insulin-responsive GLUT, acid synthase and phosphoenol pyruvate carboxykinase genes, and inhibition of the expression of the " $o b$ " gene, which encodes for leptin in MS rats (Collino et al. 2010) or in patients with MS (Haque 2012), by modulation of plasma high-molecular-weight adiponectin concentrations $(\mathrm{Vu}$ et al. 2016) or by up-regulation of maternally expressed 3 expression that protect endothelial progenitor cells (Liu et al. 2016).

Adding telmisartan to pioglitazone resulted in insignificant changes in mean serum glucose and insulin levels from those produced by pioglitazone alone, indicating that both of them regulate blood glucose and insulin level through PPAR $\gamma$ partial agonistic activity. 
Although Telmisartan attenuated the pioglitazone-induced increase in fat mass, it doesn't interfere with its insulin-sensitizing properties (Zanchi et al. 2007) which is in agreement with the present results.

In the present study, telmisartan significantly decreased uric acid level that is in agreement with (Sato et al. 2008) but opposite to (Burgess and Buckley 2000) in hypertensive patients. Pioglitazone significantly decrease the uric acid that run with study of (Kutoh and Hori 2013) and (WU et al. 2011) possibly by relieving insulin resistance or may be centrally through upregulation of beta cell related factors especially in early stage type-2 diabetes (Kimura et al. 2015), this is in agreement with our results as regard IR which is significantly reduced by pioglitazone, telmisartan or their combination compared to MS non-treated group.

Telmisartan significantly decrease mean serum urea with insignificant change in mean creatinine level, this result run with Mandarim-deLacerda and Pereira, in diabetic and non-diabetic hypertensive patients (Mandarim-de-Lacerda and Pereira 2004).

On the other hand, a renoprotective effect of telmisartan is approved in streptozotocin induced diabetes (Zhang et al. 2012). Telmisartan through PPAR- $\gamma$ partial agonist activity has the ability to improve glycemic and lipid status in a high fat, high carbohydrate diet (Kakuta et al. 2004), anti-inflammatory, antioxidative and anti- 
proliferative effects on vasculature (Knight et al. 2008) that is consequently decrease glomerular damage .

The differences between these results and our results may be due to differences in drug doses used, animal models or duration of treatment.

Pioglitazone ameliorate HFD increase in serum urea and creatinine. Many evidences support the use of TZDs as renoprotective beyond their glycemic control and hypertension effects (WU et al. 2011).

Although TGF- $\beta 1$ is fundamentally released by hepatic stellate cells during chronic liver injury and plays a critical role in liver apoptosis and fibrogenesis in non-alcoholic fatty liver disease or hepatic steatosis (Tarantino et al. 2008); Weigert et al., approved the benefits of PPAR $\gamma$ agonists activity of pioglitazone in reduction of TGF- $\beta 1$ transcription induced by high glucose (Weigert et al. 2003), pioglitazone also may induce arrest of cell growth and mesangial cell differentiation (Guan et al. 2001), inhibit platelet-derived growth factor (PDGF) induced mesangial growth (Ghosh et al. 2003) and suppress of proinflammatory cytokine expression in mesangial cells (Xiong et al. 2004).

In the present study, telmisartan significantly decreased $\mathrm{TG}$, total cholesterol and LDL-c and significantly increased HDL-c compared to 
non-treated group. This is in agreement with (Ono et al. 2009) but in contrast to observation of (De Luis et al. 2010).

The improvement in lipid profile with telmisartan may be due to its PPAR $\gamma$-modulating effect (Derosa et al. 2004), with potent induction of hepatic PPAR $\alpha$-target genes involved in fatty acids catabolism (Jayapriya et al. 2013).

There is positive correlation between hyperuricemia and components of metabolic syndrome (Lin et al. 2007). Moreover, a correlation between UA and total cholesterol, TG and LDL-C and an inverse correlation with HDL-C was observed in 66 adult patients (Heimbach et al. 2012).

The mechanism by which UA may regulate lipids is unclear, may be due to decrease lipid peroxidase (Struthers et al. 2002), decrease in lipase activity (Nakagawa et al. 2006) that results in a decrease in oxidative stress harmful effect (Kanbay et al. 2007). Hyperuricemia may impair endothelium dependent vasodilatation via lipid oxidation (Osgood et al. 2003). Furthermore (Balasubramanian 2003), reported a significant direct relationship between UA and total cholesterol levels in animal models. 
The ameliorative effect of pioglitazone on HFD induced dyslipidaemia is in agreement with (Collino et al. 2010) while opposite to (Haque 2012).

Pioglitazone is "dual PPAR $\gamma$-PPAR $\alpha$ agonist (Bailey 2001), the activation to PPAR $\alpha$ has been linked to lowering TG levels (Duez et al. 2002) or as a result of PPAR $\gamma$ agonistic activity that results in hepatic inflammatory response reduction, modulation of the expression of numerous genes in adipocytes that results in improved insulin sensitivity, increased fatty acid uptake and decreased lipolysis (Bailey 2001). Hence the restoration of insulin sensitivity that contribute to dyslipidaemia improvement (Gastaldelli et al. 2009).

The hyperuricemia associated with MS affected the knee joint of two rats of the examined animals in the positive control group (B1) that showed features of acute gouty arthritis in the form of edema, moderate to mild neutrophils and mast cells infiltration within the periarticular soft tissues compared to animals of the negative control group (A) that showed normal structure of the examined knee joints with no detection of any lesion.

The hypouricemic effect of both telmisartan and pioglitazone was supported by histopathological study of all animals in the remaining 
groups (B2, B4, and B6) where no lesions of gouty arthritis were detected within the articular and periarticular soft tissues.

This could be explained partly by hypouricemic activity of both pioglitazone and telmisartan together with their anti-inflammatory effects.

Similarly, (Al-Hejjaj et al. 2011) showed anti-inflammatory effect of telmisartan and suggested that telmisartan may possess anti-proliferative and anti-arthritic activities in rat models of chronic inflammation induced by formaldehyde- and cotton pellet.

The antioxidant and anti-inflammatory effects of telmisartan are related to its ability to prevent the activation of NF- $\mathrm{BB}$ signalling pathway which promotes the transcription of NADPH oxidase, TNF- $\alpha$ and inducible nitric oxide synthase genes (Morishima et al. 2009), resulting in induction of gene expression, decrease oxidative stress and amelioration of proinflammatory responses as a results of a partial agonistic activity of the PPAR- $\gamma$ (Blessing et al. 2008) as a result of a PPAR- $\gamma$ partial agonistic activity (Benson et al. 2004)

Pioglitazone produced a significant improvement of serum oxidative stress parameters and inflammatory cytokines in treatment of collagen induced rheumatoid arthritis in rats (Shahin et al. 2011). Pioglitazone act 
as ligands for the PPAR- $\gamma$ which is important immunomodulator that suppresses the production of inflammatory cytokines (Larsen et al. 2003), reactive oxygen species (Hwang et al. 2005) and inhibits proinflammatory gene expression (Verrier et al. 2004).

In summary; both of telmisartan and pioglitazone ameliorated MS and the associated hypertension induced by HFR in rats. The protective effect of either drug was accompanied by significant amelioration in glucose, insulin, IR, dyslipidaemia. Pioglitazone is more superior to telmisartan in controlling levels of blood glucose and insulin, IR reduction and in renal protection, whereas telmisartan is more effective than pioglitazone in controlling $\mathrm{BP}$ and $\mathrm{BW}$, combined drugs showed better control of $\mathrm{BW}$ and hypertension compared to pioglitazone alone and better renoprotective compared to telmisartan alone.

From this work we can conclude that combined telmisartan plus pioglitazone allow better control of MS manifestations as BP, hyperglycaemia, insulin resistance and the amelioration of increase in BW that may be associated with pioglitazone treatment alone 


\section{References}

Al-Hejjaj, W.K., Numan, I.T., Al-Sa'ad, R.Z., and Hussain, S.A. 2011. Anti-inflammatory activity of telmisartan in rat models of experimentally-induced chronic inflammation: Comparative study with dexamethasone. Saudi Pharmaceut. J. 19(1): 29-34.

Alam, S., Kabir, J., Mustafa, G., Gupta, U., Hasan, S., and Alam, A. 2016. Effect of telmisartan on histological activity and fibrosis of nonalcoholic steatohepatitis: A 1-year randomized control trial. Saudi J. Gastroenterol. 22(1): 69-76. doi: 10.4103/1319-3767.173762.

Bahr, I.N., Tretter, P., Kruger, J., Stark, R.G., Schimkus, J., Unger, T., Kappert, K., Scholze, J., Parhofer, K.G., and Kintscher, U. 2011. Highdose treatment with telmisartan induces monocytic peroxisome proliferator-activated receptor-gamma target genes in patients with the metabolic syndrome. Hypertension, 58(4): 725-732. doi: 10.1161/HYPERTENSIONAHA.111.173542.

Bailey, C.J. 2001. New pharmacologic agents for diabetes. Curr. Diabetes Rep. 1(2): 119-126.

Balasubramanian, T. 2003. Uric acid or 1-methyl uric acid in the urinary bladder increases serum glucose, insulin, true triglyceride, and total cholesterol levels in Wistar rats. The Scientific World Journal, 3: 930936. 
BARUTÇUOĞLU, B., Parildar, Z., MUTAF, M.I., ÖZMEN, D., ALİOĞLU, E., Habif, S., and Bayindir, O. 2010. Effect of telmisartan on vascular endothelium in hypertensive and type 2 diabetic hypertensive patients. Turk. J. Med. Sci. 40(2): 239-248.

Benson, S.C., Pershadsingh, H.A., Ho, C.I., Chittiboyina, A., Desai, P., Pravenec, M., Qi, N., Wang, J., Avery, M.A., and Kurtz, T.W. 2004. Identification of telmisartan as a unique angiotensin II receptor antagonist with selective PPARgamma-modulating activity. Hypertension, 43(5): 993-1002. doi: 10.1161/01.HYP.0000123072.34629.57.

Blessing, E., Preusch, M., Kranzhöfer, R., Kinscherf, R., Marx, N., Rosenfeld, M.E., Isermann, B., Weber, C.M., Kreuzer, J., and Gräfe, J. 2008. Anti-atherosclerotic properties of telmisartan in advanced atherosclerotic lesions in apolipoprotein $\mathrm{E}$ deficient mice. Atherosclerosis, 199(2): 295-303.

Burgess, E.D., and Buckley, S. 2000. I025: Acute natriuretic effect of telmisartan in hypertensive patients. Am. J. Hypertens. 13(S2): 183A. doi: 10.1016/s0895-7061(00)01171-7.

Collino, M., Aragno, M., Castiglia, S., Miglio, G., Tomasinelli, C., Boccuzzi, G., Thiemermann, C., and Fantozzi, R. 2010. Pioglitazone improves lipid and insulin levels in overweight rats on a high cholesterol and fructose diet by decreasing hepatic inflammation. Br. J. Pharmacol. 160(8): 1892-1902. doi: 10.1111/j.1476-5381.2010.00671.x. 
de Kloet, A.D., Krause, E.G., and Woods, S.C. 2010. The renin angiotensin system and the metabolic syndrome. Physiol. Behav. 100(5): 525-534. doi: 10.1016/j.physbeh.2010.03.018.

De Luis, D., Conde, R., González-Sagrado, M., Aller, R., Izaola, O., Duenas, A., Castrillon, J.P., and Romero, E. 2010. Effects of telmisartan vs olmesartan on metabolic parameters, insulin resistance and adipocytokines in hypertensive obese patients. Nutr. Hosp. 25(2): 275279.

Derosa, G., Ragonesi, P.D., Mugellini, A., Ciccarelli, L., and Fogari, R. 2004. Effects of telmisartan compared with eprosartan on blood pressure control, glucose metabolism and lipid profile in hypertensive, type 2 diabetic patients: a randomized, double-blind, placebo-controlled 12month study. Hypertens. Res. 27(7): 457-464.

Diamant, M., and Heine, R.J. 2003. Thiazolidinediones in type 2 diabetes mellitus: current clinical evidence. Drugs, 63(13): 1373-1405.

Dormandy, J.A., Charbonnel, B., Eckland, D.J., Erdmann, E., MassiBenedetti, M., Moules, I.K., Skene, A.M., Tan, M.H., Lefebvre, P.J., Murray, G.D., Standl, E., Wilcox, R.G., Wilhelmsen, L., Betteridge, J., Birkeland, K., Golay, A., Heine, R.J., Koranyi, L., Laakso, M., Mokan, M., Norkus, A., Pirags, V., Podar, T., Scheen, A., Scherbaum, W., Schernthaner, G., Schmitz, O., Skrha, J., Smith, U., Taton, J., and Investigators, P.R. 2005. Secondary prevention of macrovascular events 
in patients with type 2 diabetes in the PROactive Study (PROspective pioglitAzone Clinical Trial In macroVascular Events): a randomised controlled trial. Lancet, 366(9493): 1279-1289. doi: 10.1016/S0140$6736(05) 67528-9$

Duez, H., Chao, Y.-S., Hernandez, M., Torpier, G., Poulain, P., Mundt, S., Mallat, Z., Teissier, E., Burton, C.A., and Tedgui, A. 2002. Reduction of atherosclerosis by the peroxisome proliferator-activated receptor $\alpha$ agonist fenofibrate in mice. J. Biol. Chem. 277(50): 48051-48057.

Endo, Y., Suzuki, M., Yamada, H., Horita, S., Kunimi, M., Yamazaki, O., Shirai, A., Nakamura, M., Iso, O.N., Li, Y., Hara, M., Tsukamoto, K., Moriyama, N., Kudo, A., Kawakami, H., Yamauchi, T., Kubota, N., Kadowaki, T., Kume, H., Enomoto, Y., Homma, Y., Seki, G., and Fujita, T. 2011. Thiazolidinediones enhance sodium-coupled bicarbonate absorption from renal proximal tubules via PPARgamma-dependent nongenomic signaling. Cell Metab.13(5): 550-561. doi: 10.1016/j.cmet.2011.02.015.

Finelli, C., and Tarantino, G. 2012a. Have guidelines addressing physical activity been established in nonalcoholic fatty liver disease. World J. Gastroenterol. 18(46): 6790-6800.

Finelli, C., and Tarantino, G. 2012b. Is there any consensus as to what diet or lifestyle approach is the right one for NAFLD patients. J. Gastrointestin. Liver Dis. 21(3): 293-302. 
Fujimoto, M., Masuzaki, H., Tanaka, T., Yasue, S., Tomita, T., Okazawa, K., Fujikura, J., Chusho, H., Ebihara, K., Hayashi, T., Hosoda, K., and Nakao, K. 2004. An angiotensin II AT1 receptor antagonist, telmisartan augments glucose uptake and GLUT4 protein expression in 3T3-L1 adipocytes. FEBS Lett. 576(3): 492-497. doi: 10.1016/j.febslet.2004.09.027.

Galle, J., Schwedhelm, E., Pinnetti, S., Boger, R.H., Wanner, C., and investigators, V. 2008. Antiproteinuric effects of angiotensin receptor blockers: telmisartan versus valsartan in hypertensive patients with type 2 diabetes mellitus and overt nephropathy. Nephrol. Dial. Transplant. 23(10): 3174-3183. doi: 10.1093/ndt/gfn230.

Gastaldelli, A., Casolaro, A., Ciociaro, D., Frascerra, S., Nannipieri, M., Buzzigoli, E., and Ferrannini, E. 2009. Decreased whole body lipolysis as a mechanism of the lipid-lowering effect of pioglitazone in type 2 diabetic patients. Am. J. Physiol. 297(1): E225-E230.

Ghosh, S.S., Gehr, T.W., Ghosh, S., Fakhry, I., Sica, D.A., Lyall, V., and Schoolwerth, A.C. 2003. PPAR\&ggr; ligand attenuates PDGF-induced mesangial cell proliferation: Role of MAP kinase. Kidney Int.64(1): 5262.

Goke, B., and German Pioglitazone Study, G. 2002. Improved glycemic control and lipid profile in a randomized study of pioglitazone compared 
with acarbose in patients with type 2 diabetes mellitus. Treatments in endocrinology, 1(5): 329-336.

Guan, Y., Zhang, Y., Schneider, A., Davis, L., Breyer, R.M., and Breyer, M.D. 2001. Peroxisome proliferator-activated receptor- $\gamma$ activity is associated with renal microvasculature. Am. J. Physiol. 281(6): F1036F1046.

Haque, S. 2012. Peroxisome Proliferators Activated Receptor- $\gamma$ Agonists:

Pioglitazone and Telmisartan; potential therapeutic approaches to the Metabolic Syndrome. J. Diabetol. 1: 2.

Heimbach, E.J., Rodney G. Bowden, , Jackson O. Griggs, . Alexander Beaujean, Eva I. Doyle, Robert D. Doyle. 2012. The Effects of Lowering Uric Acid Levels Using Allopurinol on Components of Metabolic Syndrome. Cardiol. Res. 3(2): 80-86. doi: 10.4021/cr168w.

Hwang, J., Kleinhenz, D.J., Lassègue, B., Griendling, K.K., Dikalov, S., and Hart, C.M. 2005. Peroxisome proliferator-activated receptor- $\gamma$ ligands regulate endothelial membrane superoxide production. Am. J. Physiol. 288(4): C899-C905.

Jayapriya, B., Thamilarasi, S., Shanthi, M., and Jafrin, A.L. 2013. Effect of telmisartan on blood pressure and lipid profile in hypertensive patients with dyslipidemia. Int. J. Clin. Pharmacol. Res. 4(10).

Kakuta, H., Sudoh, K., Sasamata, M., and Yamagishi, S. 2004. Telmisartan has the strongest binding affinity to angiotensin II type 1 
receptor: comparison with other angiotensin II type 1 receptor blockers. Int. J. Clin. Pharmacol. Res. 25(1): 41-46.

Kanbay, M., Ozkara, A., Selcoki, Y., Isik, B., Turgut, F., Bavbek, N., Uz, E., Akcay, A., Yigitoglu, R., and Covic, A. 2007. Effect of treatment of hyperuricemia with allopurinol on blood pressure, creatinine clearence, and proteinuria in patients with normal renal functions. Int. Urol. Nephrol. 39(4): 1227-1233.

Kelishadi, R., Mansourian, M., and Heidari-Beni, M. 2014. Association of fructose consumption and components of metabolic syndrome in human studies: a systematic review and meta-analysis. Nutrition, 30(5): 503-510. doi: 10.1016/j.nut.2013.08.014.

Khan, A.R., Al Abdul Lateef, Z.N., Khamseen, M.B., Al Aithan, M.A., Khan, S.A., and Al Ibrahim, I. 2011. Knowledge, attitude and practice of ministry of health primary health care physicians in the management of type 2 diabetes mellitus: a cross-sectional study in the Al Hasa District of Saudi Arabia, 2010. Nigerian J. Clin. Pract. 14(1): 52-59. doi: 10.4103/1119-3077.79241.

Kimura, T., Kaneto, H., Shimoda, M., Hirukawa, H., Okauchi, S., Kohara, K., Hamamoto, S., Tawaramoto, K., Hashiramoto, M., and Kaku, K. 2015. Protective effects of pioglitazone and/or liraglutide on pancreatic beta-cells in $\mathrm{db} / \mathrm{db}$ mice: Comparison of their effects between 
in an early and advanced stage of diabetes. Mol. Cell. Endocrinol. 400: 78-89. doi: 10.1016/j.mce.2014.11.018.

Knight, S.F., Quigley, J.E., Yuan, J., Roy, S.S., Elmarakby, A., and Imig, J.D. 2008. Endothelial dysfunction and the development of renal injury in spontaneously hypertensive rats fed a high-fat diet. Hypertension, 51(2): 352-359.

Knorr, M., Hausding, M., Kroller-Schuhmacher, S., Steven, S., Oelze, M., Heeren, T., Scholz, A., Gori, T., Wenzel, P., Schulz, E., Daiber, A., and Munzel, T. 2011. Nitroglycerin-induced endothelial dysfunction and tolerance involve adverse phosphorylation and S-Glutathionylation of endothelial nitric oxide synthase: beneficial effects of therapy with the AT1 receptor blocker telmisartan. Arterioscler., Thromb., Vasc. Biol. 31(10): 2223-2231. doi: 10.1161/ATVBAHA.111.232058.

Kong, X., Ma, M.Z., Qin, L., Zhang, Y., Li, X.Y., Wang, G.D., Su, Q., and Zhang, D.Y. 2014. Pioglitazone enhances the blood pressurelowering effect of losartan via synergistic attenuation of angiotensin IIinduced vasoconstriction. Journal of the renin-angiotensin-aldosterone system : JRAAS 15(3): 259-270. doi: 10.1177/1470320313489061.

Kutoh, E., and Hori, T. 2013. Effect of Pioglitazone on Serum Uric Acid Levels in Newly Diagnosed, Drug-Naive Patients with Type 2 Diabetes. Endocr. Res. 38(3): 151-159. doi: 10.3109/07435800.2012.745128. 
Lardizabal, J.A., and Deedwania, P.C. 2010. The role of reninangiotensin agents in altering the natural history of type 2 diabetes mellitus. Curr. Cardiol. Rep. 12(6): 464-471. doi: 10.1007/s11886-0100138-1.

Larsen, T., Toubro, S., and Astrup, A. 2003. PPARgamma agonists in the treatment of type II diabetes: is increased fatness commensurate with long-term efficacy? Int. J. Obes. 27(2): 147-161.

Lin, J.D., Chiou, W.K., Chang, H.Y., Liu, F.H., and Weng, H.F. 2007. Serum uric acid and leptin levels in metabolic syndrome: a quandary over the role of uric acid. Metabolism, 56(6): 751-756. doi: 10.1016/j.metabol.2007.01.006.

Little, P.J., Ballinger, M.L., Survase, S., Osman, N., Ogru, E., Geytenbeek, S., Bruemmer, D., and Nigro, J. 2008. Phosphorylated troglitazone activates PPARgamma and inhibits vascular smooth muscle cell proliferation and proteoglycan synthesis. J. Cardiovasc. Pharmacol. 51(3): 274-279. doi: 10.1097/FJC.0b013e3181626ce7.

Liu, H.Z., Wang, Q.Y., Zhang, Y., Qi, D.T., Li, M.W., Guo, W.Q., Ma, Y.H., Wang, L.Y., Chen, Y., and Gao, C.Y. 2016. Pioglitazone upregulates long non-coding RNA MEG3 to protect endothelial progenitor cells via increasing HDAC7 expression in metabolic syndrome. Biomed. Pharmacother. 78: 101-109. doi: 10.1016/j.biopha.2016.01.001. 
Mandarim-de-Lacerda, C.A., and Pereira, L.M. 2004. Effect of telmisartan on preexistent cardiac and renal lesions in spontaneously hypertensive mature rats. Histol. Histopathol. 19(3): 727-733.

Matthews, D.R., Hosker, J.P., Rudenski, A.S., Naylor, B.A., Treacher, D.F., and Turner, R.C. 1985. Homeostasis model assessment: insulin resistance and beta-cell function from fasting plasma glucose and insulin concentrations in man. Diabetologia, 28(7): 412-419.

Mazzali, M., Hughes, J., Kim, Y.G., Jefferson, J.A., Kang, D.H., Gordon, K.L., Lan, H.Y., Kivlighn, S., and Johnson, R.J. 2001. Elevated uric acid increases blood pressure in the rat by a novel crystal-independent mechanism. Hypertension, 38(5): 1101-1106.

Miyazaki, Y., and DeFronzo, R.A. 2008. Rosiglitazone and pioglitazone similarly improve insulin sensitivity and secretion, glucose tolerance and adipocytokines in type 2 diabetic patients. Diabetes, Obes. Metab. 10(12): 1204-1211. doi: 10.1111/j.1463-1326.2008.00880.x.

Mori, Y., Itoh, Y., and Tajima, N. 2007. Angiotensin II receptor blockers downsize adipocytes in spontaneously type 2 diabetic rats with visceral fat obesity. Am. J. Hypertens. 20(4): 431-436. doi: 10.1016/j.amjhyper.2006.09.016.

Morishima, M., Wang, Y., Akiyoshi, Y., Miyamoto, S., and Ono, K. 2009. Telmisartan, an angiotensin II type 1 receptor antagonist, attenuates 
T-type Ca $2+$ channel expression in neonatal rat cardiomyocytes. Eur. J. Pharmacol. 609(1): 105-112.

Nagi, M.N., al-Bekairi, A.M., and al-Sawaf, H.A. 1995. Spectrophotometric assay for superoxide dismutase based on the nitroblue tetrazolium reduction by glucose-glucose oxidase. Biochem. Mol. Biol. Int. 36(3): 633-638.

Nakagawa, T., Hu, H., Zharikov, S., Tuttle, K.R., Short, R.A., Glushakova, O., Ouyang, X., Feig, D.I., Block, E.R., and Herrera-Acosta, J. 2006. A causal role for uric acid in fructose-induced metabolic syndrome. Am. J. Physiol. 290(3): F625-F631.

Olefsky, J.M. 2000. Treatment of insulin resistance with peroxisome proliferator-activated receptor gamma agonists. J. Clin. Invest. 106(4): 467-472. doi: 10.1172/JCI10843.

Ono, Y., Nakaya, Y., Bando, S., Soeki, T., Ito, S., and Sata, M. 2009. Telmisartan decreases plasma levels of asymmetrical dimethyl-L-arginine and improves lipid and glucose metabolism and vascular function. Int. Heart J. 50(1): 73-83.

Osgood, D., Corella, D., Demissie, S., Cupples, L.A., Wilson, P.W., Meigs, J.B., Schaefer, E.J., Coltell, O., and Ordovas, J.M. 2003. Genetic variation at the scavenger receptor class B type I gene locus determines plasma lipoprotein concentrations and particle size and interacts with type 
2 diabetes: the framingham study. J. Clin. Endocrinol. Metab. 88(6): 2869-2879.

Puig, J.G., and Martinez, M.A. 2008. Hyperuricemia, gout and the metabolic syndrome. Curr. Opin. Rheumatol. 20(2): 187-191. doi: 10.1097/BOR.0b013e3282f4b1ed.

Rabie, E.M., Heeba, G.H., Abouzied, M.M., and Khalifa, M.M. 2015. Comparative effects of Aliskiren and Telmisartan in high fructose dietinduced metabolic syndrome in rats. Eur. J. Pharmacol. 760: 145-153. doi: 10.1016/j.ejphar.2015.04.019.

Sanchez-Lozada, L.G., Tapia, E., Santamaria, J., Avila-Casado, C., Soto, V., Nepomuceno, T., Rodriguez-Iturbe, B., Johnson, R.J., and HerreraAcosta, J. 2005. Mild hyperuricemia induces vasoconstriction and maintains glomerular hypertension in normal and remnant kidney rats. Kidney Int. 67(1): 237-247. doi: 10.1111/j.1523-1755.2005.00074.x.

Sato, M., Iwanaga, T., Mamada, H., Ogihara, T., Yabuuchi, H., Maeda, T., and Tamai, I. 2008. Involvement of uric acid transporters in alteration of serum uric acid level by angiotensin II receptor blockers. Pharmaceut. Res. 25(3): 639-646. doi: 10.1007/s11095-007-9401-6.

Schupp, M., Janke, J., Clasen, R., Unger, T., and Kintscher, U. 2004. Angiotensin type 1 receptor blockers induce peroxisome proliferatoractivated receptor-gamma activity. Circulation, 109(17): 2054-2057. doi: 10.1161/01.CIR.0000127955.36250.65. 
Shahin, D., El Toraby, E., Abdel-Malek, H., Boshra, V., Elsamanoudy, A.Z., and Shaheen, D. 2011. Effect of peroxisome proliferator-activated receptor gamma agonist (pioglitazone) and methotrexate on disease activity in rheumatoid arthritis (experimental and clinical study). Clin. Med. Insights: Arthritis Musculoskeletal Disord. 4: 1.

Sharma, A.M., Janke, J., Gorzelniak, K., Engeli, S., and Luft, F.C. 2002. Angiotensin blockade prevents type 2 diabetes by formation of fat cells. Hypertension, 40(5): 609-611.

Shokouh, P., Joharimoghadam, A., Roohafza, H., Sadeghi, M., Golabchi, A., Boshtam, M., and Sarrafzadegan, N. 2013. Effects of Pioglitazone on Asymmetric Dimethylarginine and Components of the Metabolic Syndrome in Nondiabetic Patients (EPICAMP Study): A Double-Blind, Randomized Clinical Trial. PPAR Res. 2013: 358074. doi: $10.1155 / 2013 / 358074$

Struthers, A., Donnan, P., Lindsay, P., McNaughton, D., Broomhall, J., and MacDonald, T. 2002. Effect of allopurinol on mortality and hospitalisations in chronic heart failure: a retrospective cohort study. Heart, 87(3): 229-234.

Sung, B.H., Izzo, J.L., Jr., Dandona, P., and Wilson, M.F. 1999. Vasodilatory effects of troglitazone improve blood pressure at rest and during mental stress in type 2 diabetes mellitus. Hypertension, 34(1): 8388. 
Suzuki, H., Sakamoto, M., Hayashi, T., Iuchi, H., Ohashi, K., Isaka, T., Sakamoto, N., Kayama, Y., Tojo, K., Yoshimura, M., and Utsunomiya, K. 2013. Effects of co-administration of candesartan with pioglitazone on inflammatory parameters in hypertensive patients with type 2 diabetes mellitus: a preliminary report. Cardiovasc. Diabetol.12: 71. doi: $10.1186 / 1475-2840-12-71$

Suzuki, M., Nomura, C., Odaka, H., and Ikeda, H. 1997. Effect of an insulin sensitizer, pioglitazone, on hypertension in fructose-drinking rats. Jpn. J. Pharmacol. 74(4): 297-302.

Tarantino, G., Conca, P., Riccio, A., Tarantino, M., Di Minno, M.N., Chianese, D., Pasanisi, F., Contaldo, F., Scopacasa, F., and Capone, D. 2008. Enhanced serum concentrations of transforming growth factorbeta1 in simple fatty liver: is it really benign? J. Transl. Med. 6: 72. doi: 10.1186/1479-5876-6-72.

Verrier, E., Wang, L., Wadham, C., Albanese, N., Hahn, C., Gamble, J.R., Chatterjee, V.K.K., Vadas, M.A., and Xia, P. 2004. PPAR $\gamma$ Agonists Ameliorate Endothelial Cell Activation via Inhibition of DiacylglycerolProtein Kinase C Signaling Pathway Role of Diacylglycerol Kinase. Circ. Res. 94(11): 1515-1522.

Vu, A., Kosmiski, L.A., Beitelshees, A.L., Prigeon, R., Sidhom, M.S., Bredbeck, B., Predhomme, J., Deininger, K.M., and Aquilante, C.L. 2016. Pharmacodynamic Effects of Low-Dose Pioglitazone in Patients 
with the Metabolic Syndrome without Diabetes Mellitus. Pharmacotherapy, doi: 10.1002/phar.1713.

Watanabe, S., Kang, D.H., Feng, L., Nakagawa, T., Kanellis, J., Lan, H., Mazzali, M., and Johnson, R.J. 2002. Uric acid, hominoid evolution, and the pathogenesis of salt-sensitivity. Hypertension, 40(3): 355-360.

Weigert, C., Brodbeck, K., Bierhaus, A., Häring, H.U., and Schleicher, E.D. 2003. c-Fos-driven transcriptional activation of transforming growth factor $\beta-1$ : inhibition of high glucose-induced promoter activity by thiazolidinediones. Biochem. Biophys. Res. Commun. 304(2): 301-307.

Werner, C., Baumhakel, M., Teo, K.K., Schmieder, R., Mann, J., Unger, T., Yusuf, S., and Bohm, M. 2008. RAS blockade with ARB and ACE inhibitors: current perspective on rationale and patient selection. Clin. Res. Cardiol. 97(7): 418-431. doi: 10.1007/s00392-008-0668-3.

WU, S., GENG, X., ZHOU, Y., and WANG, L. 2011. Effects of Pioglitazone, Repaglinide or Metformin on Blood Uric Acid and Renal Function in Recent-onset Type 2 Diabetes [J]. Chinese Journal of Modern Applied Pharmacy, 2: 027.

Xiong, Z., Huang, H., Li, J., Guan, Y., and Wang, H. 2004. Antiinflammatory effect of PPARgamma in cultured human mesangial cells. Renal Fail. 26(5): 497-505.

Xu, L., and Liu, Y. 2013. Administration of telmisartan reduced systolic blood pressure and oxidative stress probably through the activation of 
$\mathrm{PI} 3 \mathrm{~K} / \mathrm{Akt} / \mathrm{eNOS}$ pathway and NO release in spontaneously hypertensive rats. Physiol. Res. 62(4): 351-359.

Yuen, C.Y., Wong, W.T., Tian, X.Y., Wong, S.L., Lau, C.W., Yu, J., Tomlinson, B., Yao, X., and Huang, Y. 2011. Telmisartan inhibits vasoconstriction via PPARgamma-dependent expression and activation of endothelial nitric oxide synthase. Cardiovasc. Res. 90(1): 122-129. doi: $10.1093 / \mathrm{cvr} / \mathrm{cvq} 392$.

Zanchi, A., Dulloo, A.G., Perregaux, C., Montani, J.P., and Burnier, M. 2007. Telmisartan prevents the glitazone-induced weight gain without interfering with its insulin-sensitizing properties. Am. J. Physiol. 293(1): E91-95. doi: 10.1152/ajpendo.00024.2007.

Zhang, Q., Xiao, X., Li, M., Li, W., Yu, M., Zhang, H., Sun, X., Mao, L., and Xiang, H. 2012. Telmisartan improves kidney function through inhibition of the oxidative phosphorylation pathway in diabetic rats. J. Mol. Endocrinol. 49(1): 35-46. 


\section{Table (1): Body Weight of the Studied Groups}

\begin{tabular}{|c|c|c|c|c|c|}
\hline & Group & Group B1 & Group B2 & Group B3 & Group B4 \\
\hline BW & $194.6 \pm$ & $196.2 \pm 6.3$ & $200.1 \pm 3.1$ & $199.1 \pm 5.1$ & $197.9 \pm 7.3$ \\
$(\mathrm{gm}) 1^{\text {st }}$ & 2.9 & & & & \\
week & & & & & \\
\hline BW(gm) & $271 \pm$ & $328.6 \pm 13.7$ & $298.6 \pm 7$ & $334.1 \pm 9$ & $300.7 \pm 9.2$ \\
$8^{\text {th }}$ Week & 5.8 & $*$ & $*$ & $*_{\ddagger}$ & $*$ \\
\hline
\end{tabular}

- Each group $=7$ rats, data expressed as Mean \pm SD.

* Significant compared to group A1 $(P$ value $<0.05)$.

+ Significant compared to group B1 $(P$ value $<0.05)$.

‡ Significant compared to group B2 $(P$ value $<0.05)$. 
Table (2): Blood Pressure of the Studied Groups.

\begin{tabular}{|c|c|c|c|c|c|}
\hline & Group A1 & $\begin{array}{c}\text { Group } \\
\text { B1 }\end{array}$ & $\begin{array}{c}\text { Group } \\
\text { B2 }\end{array}$ & $\begin{array}{c}\text { Group } \\
\text { B3 }\end{array}$ & $\begin{array}{c}\text { Group } \\
\text { B4 }\end{array}$ \\
\hline $\begin{array}{l}\text { Systolic } \\
(\mathrm{mmHg})\end{array}$ & $119.3 \pm 1.5$ & $\begin{array}{l}173.4 \pm 9 . \\
6 *\end{array}$ & $\begin{array}{l}135.3 \pm 5 . \\
5 * \dagger\end{array}$ & $\begin{array}{l}138.3 \\
\pm 8.2 * \dagger\end{array}$ & $\begin{array}{l}132.3 \pm 5 \\
* \dagger\end{array}$ \\
\hline $\begin{array}{l}\text { Diastolic } \\
(\mathrm{mmHg})\end{array}$ & $72.1 \pm 6.4$ & $\begin{array}{l}103.6 \pm 1 \\
3 *\end{array}$ & $\begin{array}{l}89.6 \pm 3.9 \\
* \dagger\end{array}$ & $\begin{array}{l}92.1 \\
\pm 3.4 * \dagger\end{array}$ & $\begin{array}{l}91.8 \pm 2 . \\
4 * \dagger\end{array}$ \\
\hline $\begin{array}{l}\text { Mean BP } \\
(\mathrm{mmHg})\end{array}$ & $87.2 \pm 4.9$ & $\begin{array}{l}124 \pm 4.6 \\
*\end{array}$ & $\begin{array}{l}104.9 \pm 3 . \\
7 * \dagger\end{array}$ & $\begin{array}{l}108 \\
\pm 4.6 * \dagger\end{array}$ & $\begin{array}{l}105.3 \\
\pm 3.2 \\
* \dagger\end{array}$ \\
\hline
\end{tabular}

- Each group $=7$ rats, data presented as Mean \pm SD

* Significant compared to group A1 $(P$ value $<0.05)$.

+ Significant compared to group B1 ( $P$ value $<0.05)$. 


\section{Table (3): Serum Glucose, Insulin and Nitric Oxide Levels}

\begin{tabular}{|c|c|c|c|c|c|}
\hline & $\begin{array}{r}\text { Group } \\
\text { A1 }\end{array}$ & Group B1 & Group B2 & Group B3 & Group B4 \\
\hline $\begin{array}{l}\text { Glucose } \\
(\mathrm{mg} / \mathrm{dl})\end{array}$ & $90.4 \pm 10.1$ & $190.7 \pm 32.1^{*}$ & $112.1 \pm 16^{*} \dagger$ & $96 \pm 6.7 \dagger \S$ & $\begin{array}{l}98.9 \pm 9.8 \\
\dagger\end{array}$ \\
\hline $\begin{array}{l}\text { Insulin } \\
(\mu \mathrm{IU} / \mathrm{ml})\end{array}$ & $1.34 \pm 0.58$ & $15.9 \pm 3.11^{*}$ & $\begin{array}{l}7.11 \pm 3.53 \\
*_{\dagger+}\end{array}$ & $\begin{array}{l}3.04 \pm 1.2 \\
\dagger \S\end{array}$ & $\begin{array}{l}4.03 \pm 2.41 \\
*_{\dagger \S}\end{array}$ \\
\hline $\begin{array}{l}\mathrm{NO} \\
(\mu \mathrm{U} / \mathrm{ml})\end{array}$ & $2.46 \pm 0.94$ & $1.9 \pm 0.38$ & $2.5 \pm 0.96$ & $2.7 \pm 1.3$ & $3.6 \pm 1.9 \dagger$ \\
\hline
\end{tabular}

- Each group $=7$ rats, data presented as Mean $\pm \mathrm{SD}$

*Significant compared to group A1 $(P$ value $<0.05)$.

t: Significant compared to group B1 $(P$ value $<0.05)$.

¥: Significant compared to group B4 $(P$ value $<0.05)$.

§: Significant compared to group B2 $(P$ value $<0.05)$. 
Table (4): Serum Uric Acid, Creatinine and Urea Levels in the Studied Groups

\begin{tabular}{|l|l|l|l|l|l|}
\hline & Group A1 & Group B1 & Group & Group & Group \\
& & & B2 & B3 & B4 \\
\hline Uric acid & $1.41 \pm 0.33$ & $4.2 \pm 1.2 *$ & $2.96 \pm 1.9$ & $2.3 \pm 0.9$ & $2.1 \pm 0.6$ \\
$(\mathrm{mg} / \mathrm{dl})$ & & & $* \dagger$ & $* \dagger$ & $\dagger$ \\
\hline Creatinine & $0.75 \pm 0.06$ & $2.3 \pm 0.6 *$ & $2.4 \pm 0.8$ & $1 \pm 0.3 \dagger ¥$ & $0.7 \pm 0.1$ \\
$(\mathrm{mg} / \mathrm{dl})$ & & & $* \dagger$ & & $\dagger \S$ \\
\hline Urea & $22.1 \pm 3.3$ & $100.3 \pm 16.03$ & 64.6 & $36.1 \pm 8.2$ & $35 \pm 4.1$ \\
$(\mathrm{mg} / \mathrm{dl})$ & & $*$ & \pm 21.5 & $\dagger \S$ & $\dagger \S$ \\
& & & $* \dagger \dagger$ & & \\
\hline
\end{tabular}

- Each group $=7$ rats, data presented as Mean \pm SD

Each group $=7$ rats, data presented as Mean \pm SD

*Significant compared to group A1 $(P$ value $<0.05)$.

†: Significant compared to group B1 $(P$ value $<0.05)$.

¥: Significant compared to group B4 ( $P$ value $<0.05)$.

$\S$ : Significant compared to group B2 ( $P$ value $<0.05)$. 
Table (5): Serum Triglycerides, Cholesterol, HDL and LDL levels in the Studied Groups.

\begin{tabular}{|l|l|l|l|l|l|}
\hline & Group A1 & Group B1 & Group B2 & Group & Group \\
& & & & B3 & B4 \\
\hline Triglycerides & $65.3 \pm 12.6$ & $137.3 \pm 25.3$ & $84.4 \pm 21.1$ & $71.7 \pm 7.7$ & $72.1 \pm 9.9$ \\
$(\mathrm{mg} / \mathrm{dl})$ & & $*$ & $*_{\dagger}$ & $\dagger$ & $\dagger$ \\
\hline Cholesterol & $78.6 \pm 6.2$ & $95.1 \pm 11.3$ & $70.3 \pm 10.7$ & $69.7 \pm 4.4$ & $77.4 \pm 7.8$ \\
$(\mathrm{mg} / \mathrm{dl})$ & & $*$ & $\dagger$ & $\dagger$ & $\dagger$ \\
\hline HDL (mg/dl) & $30.1 \pm 3.5$ & $20.3 \pm 1.8 *$ & $25.9 \pm 3.3$ & $26.3 \pm$ & $24.7 \pm$ \\
& & & $*$ & $2.7 \dagger$ & $3.8 * \dagger$ \\
\hline LDL (mg/dl) & $25 \pm 2.71$ & $40 \pm 4 . *^{*}$ & $33.9 \pm 3.6$ & $28.9 \pm 4.6$ & $31.1 \pm$ \\
& & & $*+\vdots$ & $\dagger \S$ & $3.5 * \dagger$ \\
\hline
\end{tabular}

- Each group $=7$ rats, data presented as Mean \pm SD

*Significant compared to group A1 $(P$ value $<0.05)$.

†: Significant compared to group B1 $(P$ value $<0.05)$.

¥: Significant compared to group B4 $(P$ value $<0.05)$.

§: Significant compared to group B2 $(P$ value $<0.05)$. 
Figure legends:

Figure (1): Insulin resistance of The Studied Groups

- Each group $=7$ rats, data presented as Mean \pm SD

*Significant compared to group A1 $(P$ value $<0.05)$.

$\dagger$ Significant compared to group B1 $(P$ value $<0.05)$.

Figure (2) Microscopic Picture of Rat Knee Joint of The Normal Control Group (A): Normal histological structure (A-joint cavity, B-synovial membrane, C- articular cartilage, D- periarticular soft tissue) (H\&E X200).

Figure (3): Microscopic Picture of Rat Knee Joint of Group B1 (HFD): showed features of acute gouty arthritis in the form of edema (stare), moderate to mild infiltrate of neutrophils (arrow) (H\&E X200).

Figure (4) Microscopic picture of rat knee joint of group B2 (Telmisartan treated group): Normal histological structure (A-joint cavity, B-synovial membrane, C- articular cartilage, D- periarticular soft tissue) (H\&E X200). 
Figure (5): Microscopic Picture of Rat Knee Joint of Group B3 (pioglitazone): Normal histological structure (A-joint cavity, B-synovial membrane, C- articular cartilage, D- periarticular soft tissue) (H\&E X200).

Figure (6): Microscopic Picture of Rat Knee Joint of Group B4 (Telmisartan + Pioglitazone): Normal histological structure (A-joint cavity, B-synovial membrane, C- articular cartilage, D- periarticular soft tissue) (H\&E X200). 


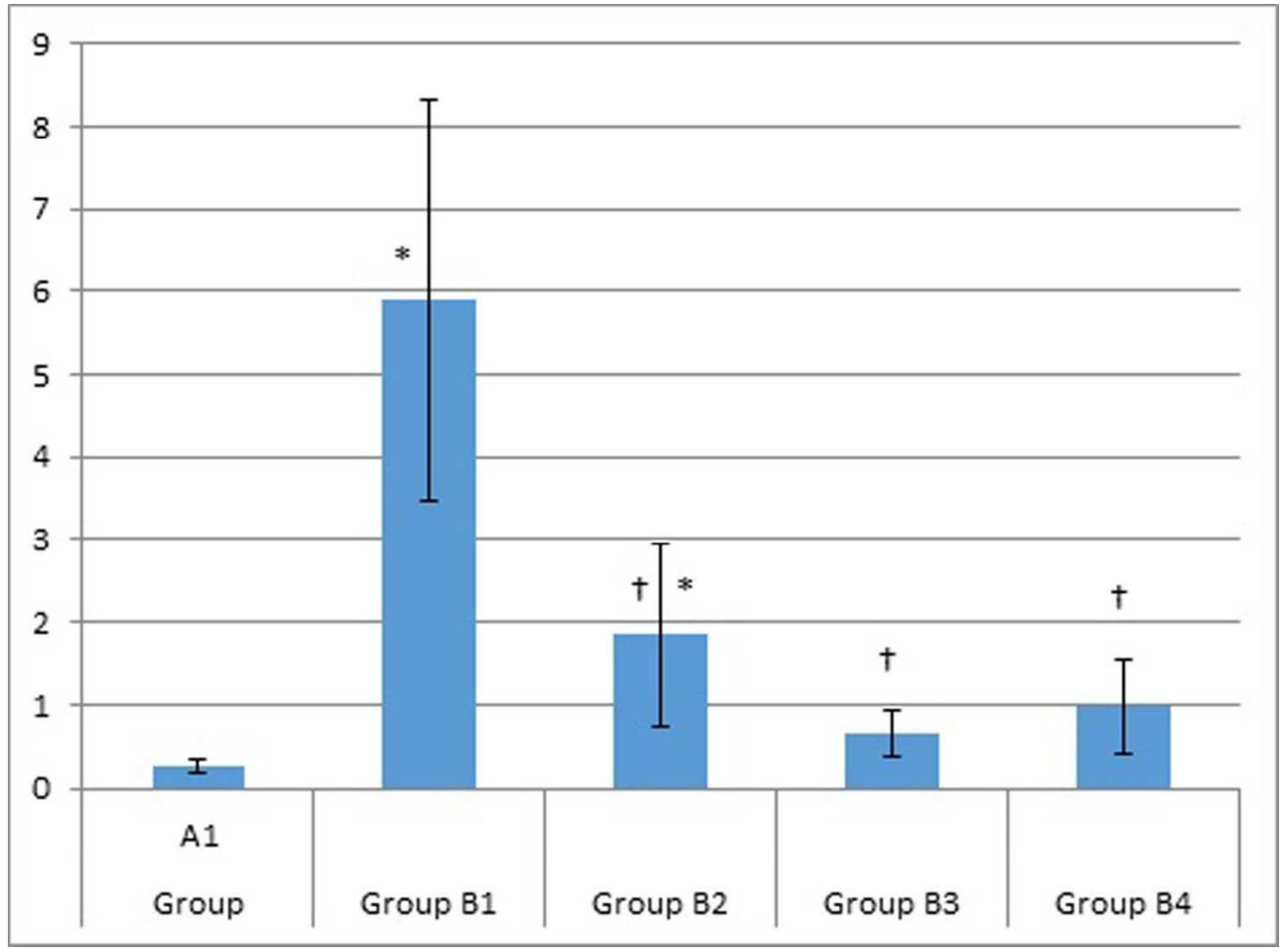

Figure 1

$124 \times 92 \mathrm{~mm}(300 \times 300$ DPI $)$ 


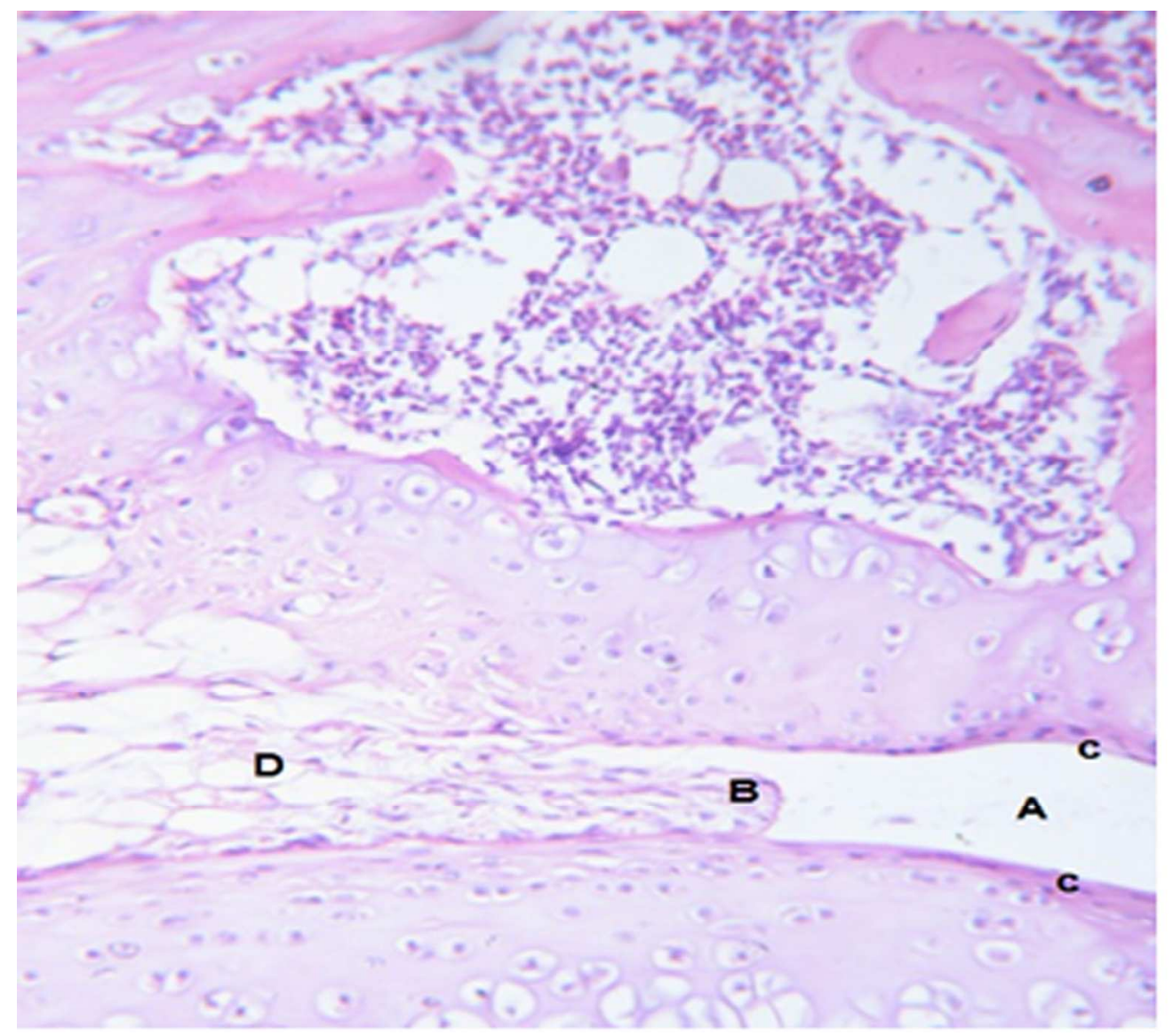

Figure 2

$130 \times 114 \mathrm{~mm}(300 \times 300 \mathrm{DPI})$ 


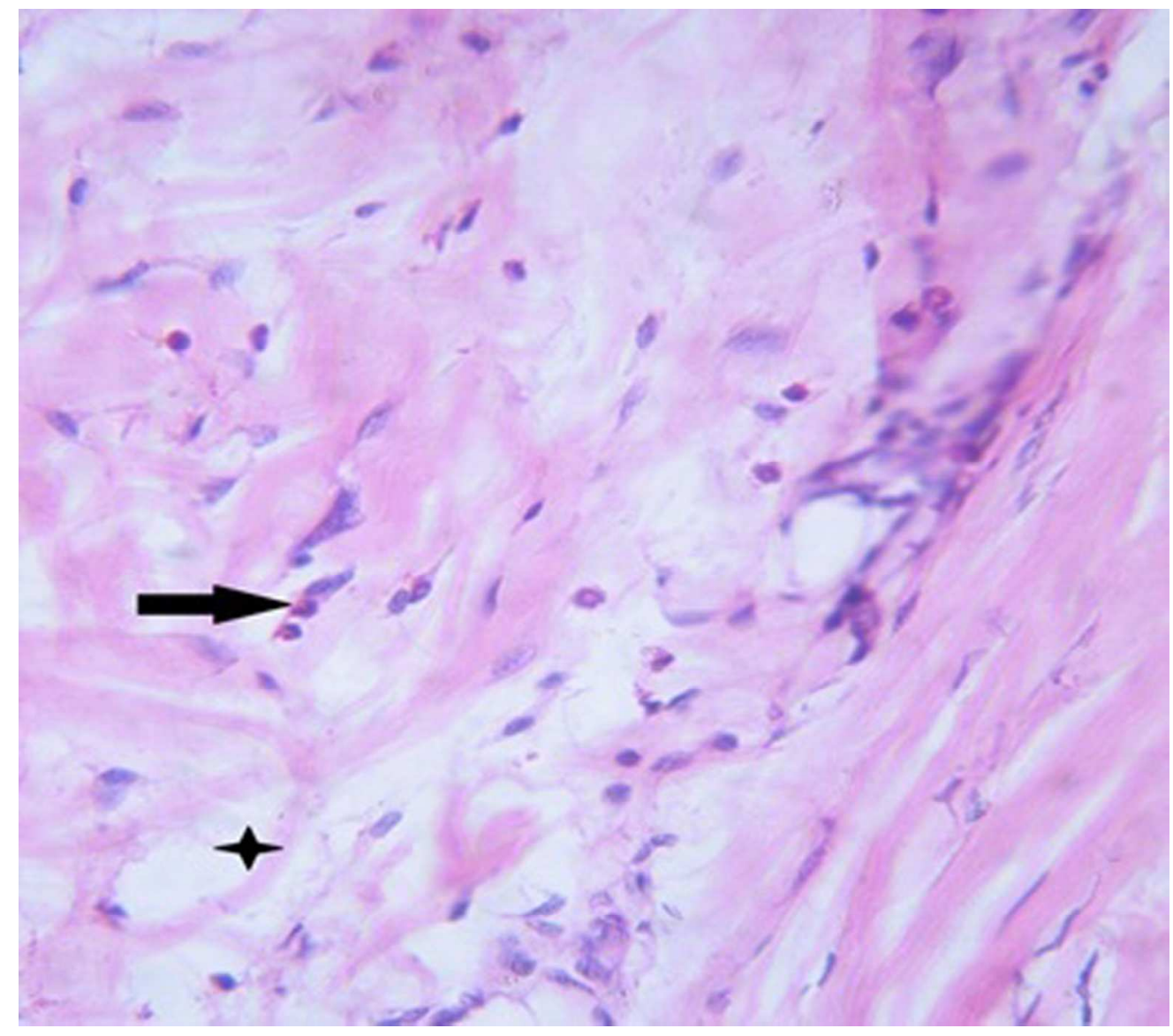

Figure 3

$98 \times 87 \mathrm{~mm}(300 \times 300$ DPI $)$ 


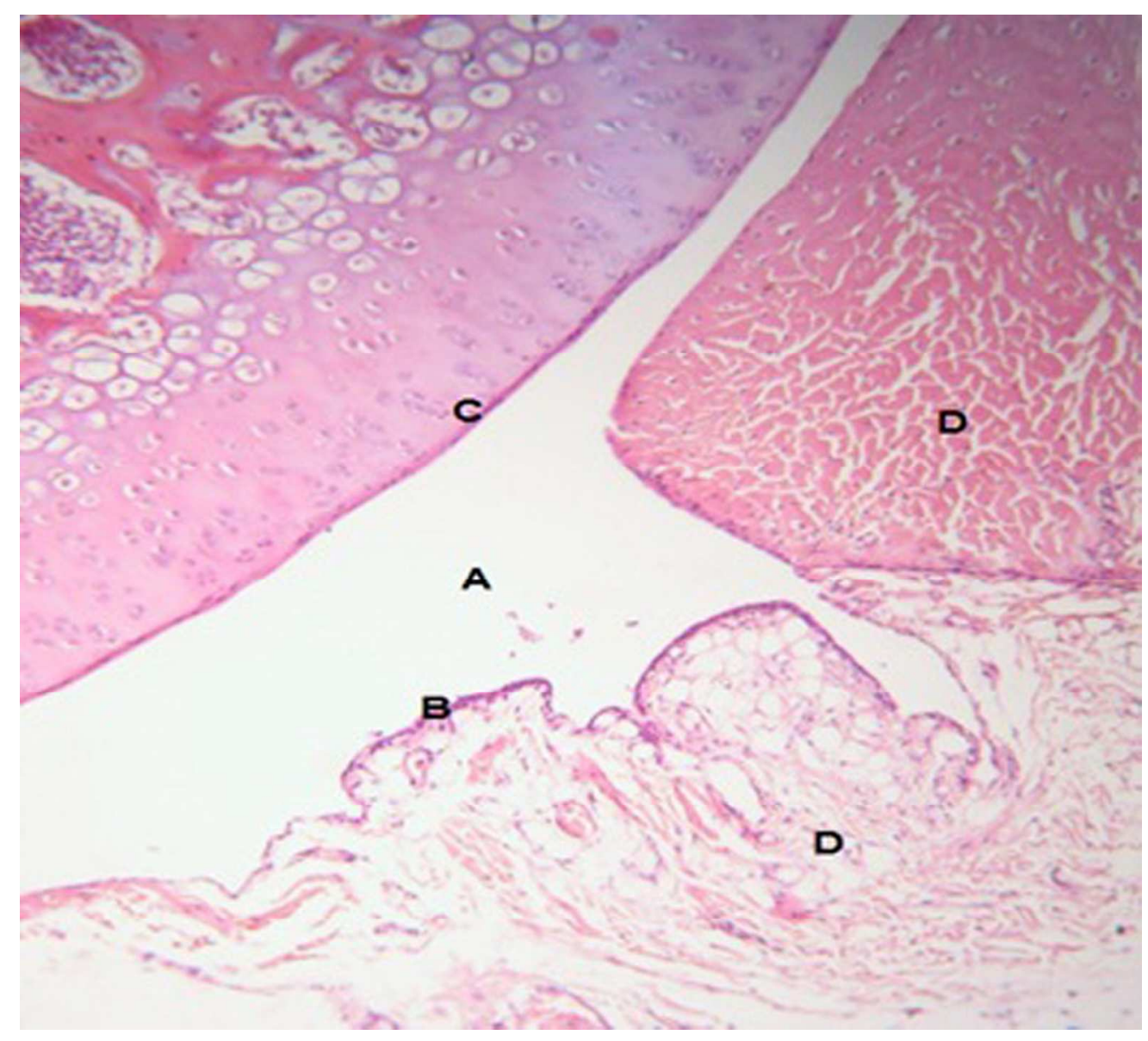

Figure 4

$99 \times 90 \mathrm{~mm}(300 \times 300$ DPI $)$ 


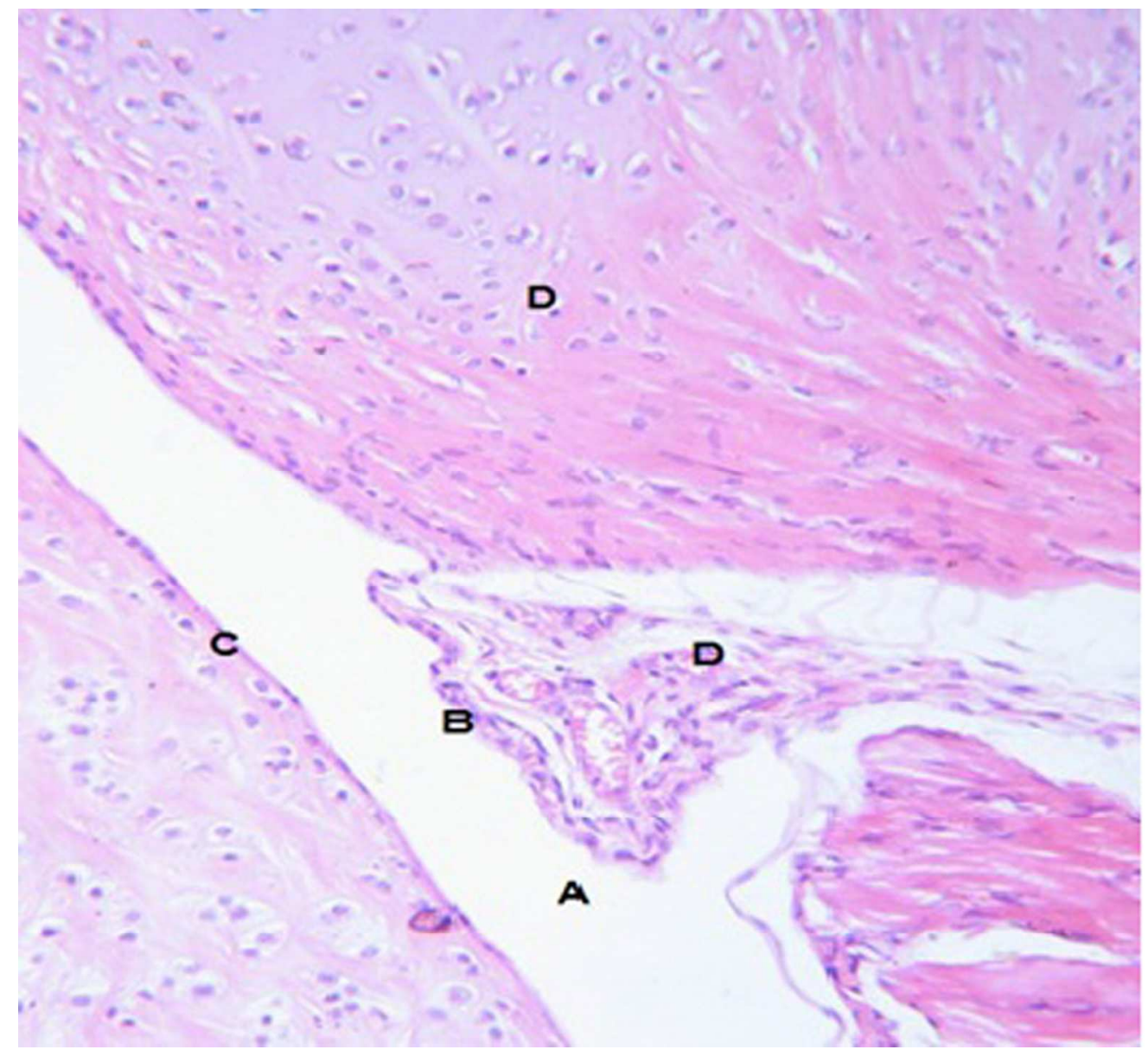

Figure 5

$97 \times 90 \mathrm{~mm}(300 \times 300 \mathrm{DPI})$ 


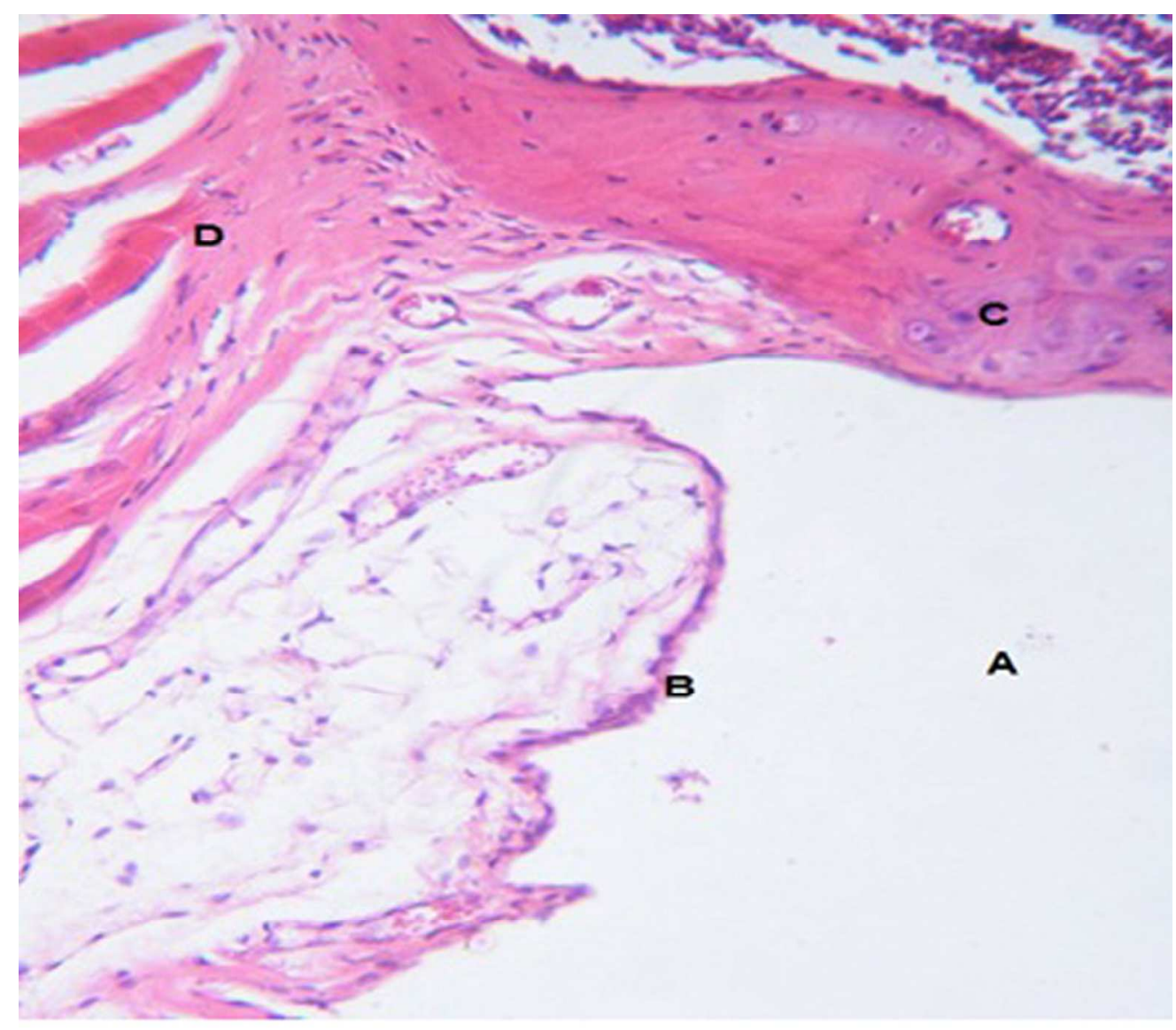

Figure 6

$102 \times 90 \mathrm{~mm}(300 \times 300 \mathrm{DPI})$ 